\title{
Long term maternal health effects of caesarean section
}

\author{
Elina Hemminki
}

\begin{abstract}
Objective-The aim was to study whether women having had caesarean sections (index women) have more subsequent health problems, measured by hospital admissions, than women having had vaginal deliveries (control women).

Design-The study involved comparison of hospital admissions before (2-5 years) and after (7-10 years) the first caesarean section (exposure) among two cohorts of index and control women.

Setting-National data from the Swedish birth and hospital discharge registries were used.
\end{abstract}

Participants-About $75 \%$ of all Swedish primiparas who had a caesarean section in $1973(n=2578)$ and in $1976(n=3822)$, and their age-matched controls, were studied; non-Swedish women and women with certain specific problems at their first birth were excluded.

Measurements and main resultsNumbers of discharges from general and mental hospitals excluding discharges relating to birth, and in some analyses to pregnancy, were determined. Total numbers of discharges from general and mental hospitals, and the numbers of discharges with operations, were higher among index than control women both before and after exposure. In analyses by diagnosis, a caesarean section was a risk factor for ectopic pregnancies and sterilisations.

Conclusions-The analyses suggest that the higher rate of hospital admission after caesarean section than after vaginal delivery is not due to the section itself, but to a continuation of a previous pattern of health service use. However, because this was not so for all diagnoses and alternative interpretations are possible, further studies on long term maternal morbidity are needed.

Regardless of the prevalence of caesarean sections ${ }^{12}$ very little is known of their long term health consequences for the mother. Decreased fertility $^{3-6}$ and increased frequency of placental problems in the next pregnancy ${ }^{7}$ have been suggested. In addition, several surveys have reported negative psychological reactions immediately after caesarean section, but data on long term effects on mental health are contradictory and do not take into account health before section (for references, $\sec ^{89}$ ).
The purpose of this study was to learn whether primiparous women having had caesarean sections have more subsequent health problems, measured by hospital admissions, than a com-parable group having had vaginal deliveries. To account for the selection bias to caesarean sections, prior hospital admissions were considered.

\section{Methods}

Two cohorts of women with caesarean sections (index women) and vaginal delivery (control women) were created according to the principle described previously. ${ }^{510}$ The index cohorts came from the Swedish birth registry, covering almost all births in Sweden ${ }^{11}$ (and personal communication from the Swedish National Board of Health, 1989). Primiparas recorded as having had caesarean sections in 1973 and 1976 were included, but women having one or more of the following in their first birth were excluded: (1) nationality other than Swedish; (2) hysterectomy or other major operation in connection with the caesarean section; (3) twins (or more infants), malformed child, child with birth weight less than $2000 \mathrm{~g}$, child's death in the perinatal period; or (4) blood group incompatibility or a serious chronic disease unrelated to pregnancy (diabetes, epilepsy, or circulatory, urogenital or sexually transmissible disease). Altogether, $24 \%$ of the primiparas who had had a caesarean section were excluded in 1973 and $25 \%$ in 1976.

For each woman in the index cohort a control was chosen among primparas without caesarean section and without any of the exclusion criteria described above, by individually matching the mother's age ( \pm one year) and child's sex (table I). Index and control women were similar with regard to the type of hospital and geographic area in which the deliveries occurred, and equal proportions delivered in hospitals participating in the hospital discharge registry. ${ }^{5}$

Information regarding health problems leading to hospital inpatient care was obtained from the discharge registry for general hospitals ${ }^{12}$ and for mental hospitals. ${ }^{13}$ Each time a patient is discharged from hospital, the diagnoses (maximum four) leading to hospital admission, operations done (maximum eight), and certain other information, including the patient's identification number, are entered in the registry; outpatient visits are not included. Internal controls on the registry show that the event of discharge is relatively well recorded, and logical mistakes in the diagnosis occur in less than 3\% (unpublished data from the Swedish National Board of Health); the accuracy of the diagnosis has not been studied. 
All mental hospitals and psychiatric departments of general hospitals participate in the mental hospital registry, and data for 1973-1983 were available for study. Not all hospitals participate in the general hospital registry, but the coverage has increased over the years, becoming $65 \%$ of discharges in 1973 and $85 \%$ in 1983 . Data were available for 1970-1983 and were used on the assumption that index and control women had moved their residence in a similar way after their first birth and were thus equally covered by the registry.

Discharge diagnoses in the registries are coded by the Swedish modification of the 1965 version of the International Classification of Diseases (ICD), ${ }^{14}$ and the operations by a Swedish classification. ${ }^{15}$ From the registry of mental hospitals, all hospital discharges specifying neurological diagnoses (ICD 320-358, 780, 781, 791.99) were counted each year for each cohort. From the registry of general hospitals, all discharges with birth diagnoses (ICD 650-662) were excluded. This was done because index women were known to have fewer and more complicated births. ${ }^{510}$ Then numbers of the following discharges were counted, including both the main and additional diagnoses: (1) total discharges; (2) with (any) operation; (3) with gynaecological operation (codes 7000-7598); (4) with sterilisation (discharge diagnosis ICD Y43, or operation codes $7111,7121,7150,7151$ ); (5) with "abdominal" operation (gastrointestinal, urinary tract etc, codes 4000-5698, 6000-6998); (6) with gynaecological diagnosis (ICD 612-629); (7) with ectopic pregnancy (ICD 631); and (8) with urinary tract diagnoses (ICD 580-599). For some analyses, women with pregnancy and puerperal diagnoses and operations (ICD 630678; main diagnosis Y1901, 6099, 6199, 6299, 6989,7109 without additional diagnosis; operation codes 7600-7888), abbreviated as pregnancy diagnoses henceforth, were excluded. The numbers of discharges, excluding pregnancy diagnoses, were counted in two ways: (1) including all discharges, and (2) including for each woman only the first discharge for that problem in each year.

Data from the registries were combined with the women's personal identification number. Wrongly coded identification numbers are apparently rare in the birth registry $(1.4 \%$ in $1974^{11}$ ), but in the hospital discharge registry identification numbers were concealed in some areas in 1971-1973 and they could not have been decoded, and a notable proportion of discharges (estimated at $25 \%$ ) cannot be linked. Since 1974,

Table I Description of the index and control women at time of first birth. Values are percentages

\begin{tabular}{|c|c|c|c|c|}
\hline & \multicolumn{2}{|l|}{1973} & \multicolumn{2}{|l|}{1976} \\
\hline & $\begin{array}{l}\text { Index } \\
(n=2578)\end{array}$ & $\begin{array}{l}\text { Control } \\
(n=2578)\end{array}$ & $\begin{array}{l}\text { Index } \\
(n=3822)\end{array}$ & $\begin{array}{l}\text { Control } \\
(n=3822)\end{array}$ \\
\hline \multicolumn{5}{|l|}{ Age (years) } \\
\hline$<20$ & $9 \cdot 5$ & $10 \cdot 3$ & 8.9 & $10 \cdot 9$ \\
\hline $20-24$ & $31 \cdot 3$ & $35 \cdot 6$ & $33 \cdot 2$ & $36 \cdot 6$ \\
\hline $25-29$ & $32 \cdot 9$ & $31 \cdot 4$ & $32 \cdot 1$ & $30 \cdot 5$ \\
\hline $30-34$ & $15 \cdot 6$ & $13 \cdot 5$ & $16 \cdot 4$ & $14 \cdot 3$ \\
\hline$\geq 35$ & $10 \cdot 7$ & $9 \cdot 2$ & $9 \cdot 5$ & $7 \cdot 7$ \\
\hline \multicolumn{5}{|l|}{ Birthweight of the infant } \\
\hline $\begin{array}{l}2000-2500 \mathrm{~g} \\
\text { Gestation length }<37 \text { weeks }\end{array}$ & $5 \cdot 2$ & $2 \cdot 6$ & $6 \cdot 1$ & $2 \cdot 2$ \\
\hline Gestation length $<37$ weeks & $5 \cdot \overline{7}$ & $4 \cdot 1$ & $6 \cdot 2$ & $4 \cdot 0$ \\
\hline
\end{tabular}

the overall proportion of wrong or missing numbers has decreased from $17 \%$ to $2 \%$ in 1983 (unpublished data from the Swedish National Board of Health). The data are used on the assumption that any mistakes in personal identification numbers are equal among the index and control women. To maintain confidentiality, all registry linkages were done within the Swedish National Board of Health, which had permission to do this. We obtained numbers of discharges in each group in each year for each cohort.

To study possible selection bias, ratios of discharges of index women to those of control women were counted separately for pre-exposure time (in the years $1970-71$ for the 1973 cohorts, and in 1970-74-or 1973-74 for mental hospitals-for the 1976 cohorts), for exposure time (years 1972-73 and 1975-76), and for postexposure time (years 1974-83 and 1977-83). The years 1972 and 1975 were combined with the exposure year, because an estimated $67 \%$ of the women were already pregnant by then. The varying numbers of subsequent pregnancies among index and control women ${ }^{5}$ were taken into account when the ratio for ectopic pregnancies was calculated. The number of births and spontaneous abortions in an eight year follow up for the 1973 cohorts (2466 for index and 2878 for control women ${ }^{5}$ ) was multiplied by 1.25 to correct for the 10 year follow up in this study. Likewise, the corresponding numbers (3612 and 4089) for the five year follow up of the 1976 cohorts were multiplied by 1.40 to correct for the seven year follow up here.

Confidence limits for the ratios were calculated as if they were risk ratios in a follow up study. ${ }^{16}$ For ectopic pregnancies the estimated numbers of pregnancies, for discharges from mental hospitals the total number of women at recruitment, and for other problems the numbers at recruitment multiplied by 0.73 (estimated coverage for the discharge registry of general hospitals) were used as numbers of index and control women. The confidence limits are only estimates, because one woman could have contributed to the events more than once. In case of all discharges, confidence intervals could not be calculated for the postexposure times, because the number of discharges was larger than the number of women.

\section{Results}

In both cohorts, the total number of discharges from general hospitals was higher among index women than among control women (table II). This was true whether all hospital discharges, excluding those with pregnancy diagnoses, or those with each woman counted only once (fig 1) were studied. The excess of discharges was more notable before and during exposure (the first caesarean section) than after it.

Index women had more discharges with gynaecological diagnoses than control women before and during exposure, but not after it (table II). Almost identical ratios were obtained when pregnancy diagnoses were excluded or when each woman was counted only once. After exposure, ectopic pregnancies were more common among index women. Urinary tract infections were more common during exposure and, in the 1976 cohort, 
also after it. If pregnancy diagnoses were excluded, the post-exposure difference emerged also for the 1973 cohort (ratio $=1 \cdot 30$, not shown in the table). Neurological diagnoses were more common among index women in all time periods studied. But when pregnancy related discharges were excluded (not shown in a table) the excess during exposure disappeared.

Discharges from mental hospitals were more common among the index women of the 1976 cohort both before and after exposure, but not during it (table II and fig 2). The difference between the index and control women was larger in later years than in the years close to exposure.

Total number of hospital discharges with operations was higher among index women than among control women, and even more so before and during than after exposure (table 3 and fig 3 ). This was true also for the subgroup "abdominal" operations. Almost identical ratios were obtained if pregnancy related diagnoses were excluded, or if each woman was counted only once.

Figure 1 Numbers of discharges from general hospitals in 1970-1983 among index women (solid line) and controls (dotted line) in 1973 (73) and 1976 (76) cohorts; each woman counted only once in each year and discharges with pregnancy related diagnoses excluded.

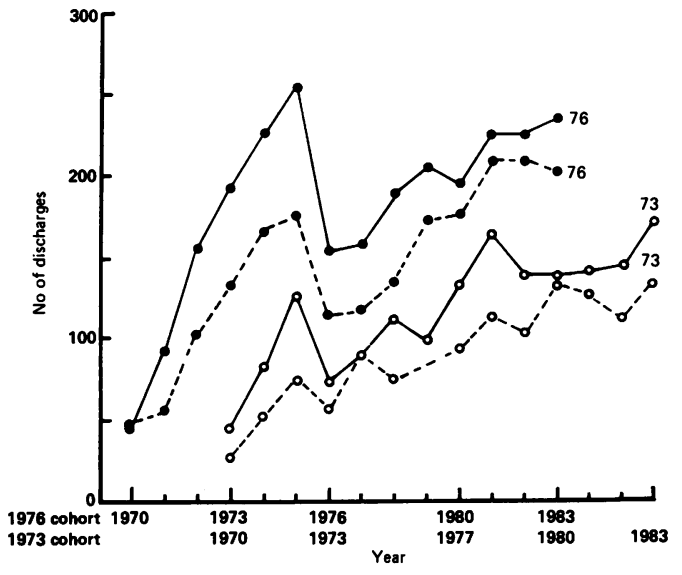

Total numbers of gynaecological operations were not more frequent after caesarean section, even though they were during, and somewhat so also before exposure (table III). Because induced abortions and sterilisations are common, and their numbers are related to the occurrence of pregnancies which varied with exposure, results in table III are also given without pregnancy related diagnoses. These analyses support the notion that gynaecological operations are a risk factor, but not a consequence of caesarean section.

Number of sterilisations was higher among index women than controls in the 1976 cohort, but not in the 1973 cohort. However, in this cohort the ratio was also higher $(1.92,95 \%$ confidence limits 0.98-3.74), if the same length of follow up (seven years) is used as for the 1976 cohort. This suggests that sterilisations are done sooner if the first birth is by caesarean section than by vaginal delivery.

\section{Discussion}

Women who had had their first birth by a caesarean section had somewhat higher long term morbidity, measured by use of hospital services, than those who had a vaginal delivery. However, with the exception of ectopic pregnancies, sterilisations, and urinary tract problems, index women had already used hospitals more before their caesarean section. This suggests that the higher use of health services, either because of poor health or for other reasons, is a risk factor for caesarean section and not its consequence; the higher rates of hospital admission after caesarean section can be considered a continuation of previous patterns.

An alternative explanation is that the use of hospital services is a risk factor for caesarean section, and ends with that birth. Then,

Table II Comparison of index and control women in regard to hospital discharges before, during, and after exposure, 1973 and 1976 cohorts ${ }^{1}$

\begin{tabular}{|c|c|c|c|c|c|c|}
\hline & \multicolumn{3}{|l|}{1973} & \multicolumn{3}{|l|}{1976} \\
\hline & Before & During & After & Before & During & After \\
\hline $\begin{array}{l}\text { All discharges from general hospitals } \\
\text { Number } \\
\text { Ratio }^{3}\end{array}$ & $\begin{array}{c}383 \\
1 \cdot 49 \\
(1 \cdot 23-1 \cdot 80)\end{array}$ & $\begin{array}{c}1220 \\
1 \cdot 68 \\
(1 \cdot 57-1 \cdot 70)\end{array}$ & $\begin{array}{l}4834 \\
1 \cdot 22 \\
-\end{array}$ & $\begin{array}{c}1935 \\
1.45 \\
(1 \cdot 35-1 \cdot 56)\end{array}$ & $\begin{array}{c}2338 \\
1 \cdot 41 \\
(1 \cdot 33-1 \cdot 50)\end{array}$ & $\begin{array}{l}5934 \\
1 \cdot 18 \\
-\end{array}$ \\
\hline $\begin{array}{l}\text { Without pregnancy diagnoses } \\
\text { Number } \\
\text { Ratio }\end{array}$ & $\begin{array}{c}257 \\
1 \cdot 57 \\
(1 \cdot 23-2 \cdot 00)\end{array}$ & $\begin{array}{c}365 \\
1.50 \\
(1 \cdot 23-1.83)\end{array}$ & $\begin{array}{c}2722 \\
1 \cdot 29 \\
(1 \cdot 24-1 \cdot 34)\end{array}$ & $\begin{array}{c}1384 \\
1 \cdot 45 \\
(1 \cdot 32-1 \cdot 59)\end{array}$ & $\begin{array}{c}775 \\
1 \cdot 49 \\
(1 \cdot 30-1 \cdot 70)\end{array}$ & $\begin{array}{c}2963 \\
1 \cdot 17 \\
(1 \cdot 11-1 \cdot 23)\end{array}$ \\
\hline $\begin{array}{l}\text { Gynaecological diagnoses } \\
\text { Number } \\
\text { Ratio }\end{array}$ & $\begin{array}{c}82 \\
2 \cdot 04 \\
(1 \cdot 29-3 \cdot 22)\end{array}$ & $\begin{array}{c}85 \\
1 \cdot 74 \\
(1 \cdot 12-2 \cdot 69)\end{array}$ & $\begin{array}{c}463 \\
1 \cdot 07 \\
(0 \cdot 90-1 \cdot 27)\end{array}$ & $\begin{array}{c}416 \\
1.62 \\
(1.34-1.96)\end{array}$ & $\begin{array}{c}216 \\
1 \cdot 73 \\
(1 \cdot 32-2 \cdot 27)\end{array}$ & $\begin{array}{c}502 \\
0 \cdot 97 \\
(0 \cdot 82-1 \cdot 14)\end{array}$ \\
\hline $\begin{array}{l}\text { Ectopic pregnancy } 4 \\
\text { Number } \\
\text { Ratio }\end{array}$ & $\frac{4}{-}$ & $\frac{1}{-}$ & $\begin{array}{c}75 \\
1 \cdot 41 \\
(0 \cdot 90-2 \cdot 21)\end{array}$ & $\begin{array}{r}12 \\
-\end{array}$ & $\begin{array}{r}17 \\
-\end{array}$ & $\begin{array}{c}64 \\
1 \cdot 65 \\
(1 \cdot 01-2 \cdot 72)\end{array}$ \\
\hline $\begin{array}{l}\text { Urinary tract diagnoses } \\
\text { Number } \\
\text { Ratio }\end{array}$ & 12 & $\begin{array}{c}27 \\
2 \cdot 86 \\
(1 \cdot 21-6 \cdot 74)\end{array}$ & $\begin{array}{c}91 \\
1 \cdot 17 \\
(0 \cdot 78-1 \cdot 76)\end{array}$ & $\begin{array}{c}95 \\
0.90 \\
(0 \cdot 60-1 \cdot 34)\end{array}$ & $\begin{array}{c}56 \\
1.95 \\
(1 \cdot 12-3 \cdot 38)\end{array}$ & $\begin{array}{c}95 \\
1 \cdot 50 \\
0 \cdot 99-2 \cdot 25)\end{array}$ \\
\hline $\begin{array}{l}\text { Neurological diagnoses } 5 \\
\text { Number } \\
\text { Ratio }\end{array}$ & $\begin{array}{l}0 \\
-\end{array}$ & $\begin{array}{r}15 \\
-\end{array}$ & $\begin{array}{c}96 \\
1 \cdot 46 \\
(0 \cdot 97-2 \cdot 18)\end{array}$ & $\begin{array}{c}37 \\
3 \cdot 11 \\
(1 \cdot 47-6 \cdot 57)\end{array}$ & $\begin{array}{c}25 \\
1.50 \\
(0 \cdot 72-3 \cdot 33)\end{array}$ & $\begin{array}{c}97 \\
1.94 \\
(1 \cdot 28-2 \cdot 94)\end{array}$ \\
\hline $\begin{array}{l}\text { All discharges from mental hospitals } \\
\text { Number } \\
\text { Ratio }\end{array}$ & - & $\begin{array}{r}19^{6} \\
-\end{array}$ & $\begin{array}{c}539 \\
1.25 \\
(1 \cdot 05-1 \cdot 45) \\
\end{array}$ & $\begin{array}{c}126^{7} \\
2 \cdot 07 \\
(1 \cdot 43-2 \cdot 99) \\
\end{array}$ & $\begin{array}{c}105 \\
0.94 \\
(0 \cdot 64-1 \cdot 37) \\
\end{array}$ & $\begin{array}{c}446 \\
1.81 \\
(1 \cdot 50-2 \cdot 18) \\
\end{array}$ \\
\hline $\begin{array}{l}1 \text { Discharges with birth diagnoses exclu } \\
\text { during }=1972-73 \text {, after }=1974-83 \text {; fo } \\
2 \text { Number of discharges for index and } \\
3 \text { Number of index women divided by } \\
4 \text { Related to number of pregnancies, s } \\
5 \text { Discharges from general and mental } \\
6 \text { Only year } 1973 \text { available } \\
7 \text { Only years } 1973-74 \text { available. }\end{array}$ & $\begin{array}{l}\text { with pregnan } \\
5 \text { cohort, befo } \\
\text { omen } \\
\text { of control wor } \\
\text { ds } \\
\text { included }\end{array}$ & $\begin{array}{l}\text { puerperal di } \\
70-74 \text {, durin } \\
\text { ounted only }\end{array}$ & $\begin{array}{l}\text { s included unl } \\
75-76, \text { after }= \\
\text { number }>2\end{array}$ & $\begin{array}{l}83 \\
\text { roximate con }\end{array}$ & $\begin{array}{l}\text { or the } 1973 \mathrm{coh} \\
\text { intervals in }\end{array}$ & $\begin{array}{l}\text { efore }=1970 \\
\text { theses }\end{array}$ \\
\hline
\end{tabular}


Figure 2 Numbers of discharges from mental hospitals in 1973-1983 among index women (solid line) and controls (dotted line) in 1973 (73) and 1976 (76) cohorts; each woman counted only once in each year.

Figure 3 Numbers of discharges from general hospitals with operations in 1970-83 among index women (solid line) and controls (dotted line) in 1973 (73) and 1976 (76) cohorts; each woman counted only once in each year and discharges with pregnancy related diagnoses excluded. independently of that prior pattern, caesarean section caused increased frequency of hospital admissions. This explanation is supported by the fact that in many cases (total hospital admissions and operations, abdominal operations) excess risk was higher before than after caesarean section, or there was no increased risk after exposure (gynaecological diagnoses and operations).

The findings of increased frequency of ectopic pregnancies after caesarean section is interesting, because in many countries there is an epidemic of
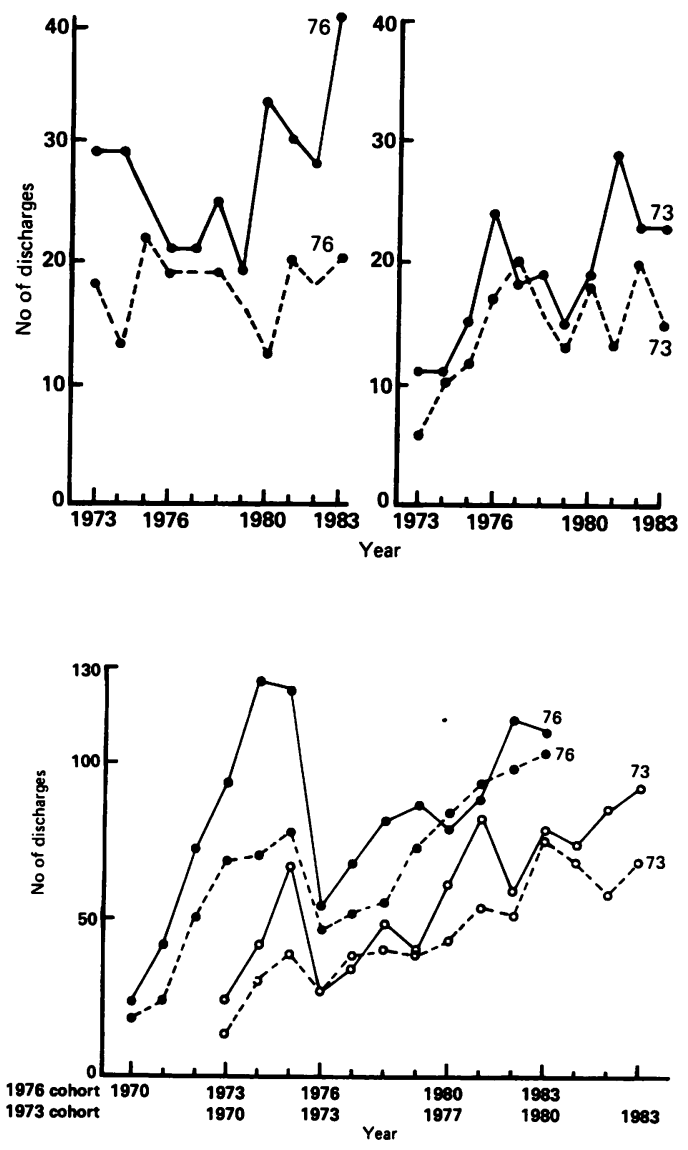

ectopic pregnancies, ${ }^{17}$ the aetiology of which is unknown, and there is a temporal relationship between ectopic pregnancies and caesarean sections (Hemminki, unpublished data). Using the risk ratio of the 1976 cohorts $(1.65)$ and an estimated caesarean section rate of $22 \%, 13 \%$ of ectopic pregnancies among multiparas could be explained by a previous caesarean section (aetiologic fraction ${ }^{16}$ ). Previous authors reporting the relation between caesarean section and ectopic pregnancy have not found an increased risk, ${ }^{18-22}$ but none of them had a comparable control group.

In our data, sterilisations were done sooner after caesarean section than after a vaginal delivery. Furthermore, at least in the United States, sterilisations have been done more commonly in connection with caesarean sections than with other births. ${ }^{23}$ Because our data did not include these sterilisations, the actual difference between the index and control women may have been even larger.

In contrast to previously published data on postpartum admissions to mental hospitals, ${ }^{24}$ the number of discharges from mental hospitals was not higher in the years of the first birth or the subsequent year than it was before or after that period. A potential explanation for this finding in 1973 and 1976 could be that the use of mental hospitals was exceptionally low during pregnancy, and that any potential increase after delivery was hidden in the data combining the pregnancy and delivery time. But the rate was also low in 1974 and 1977, when apparently very few of the women were pregnant again. Another explanation is that discharges do not measure hospital admissions accurately. It is possible that women admitted after delivery had a lengthy stay in a mental hospital and were discharged years later.

Because of methodological drawbacks of this study, all the data and their interpretations have to be considered with caution.

First, index and control women were made similar only by exclusions and matching for age. Table III Comparison of index and control women in regard to hospital discharges indicating operations, before, during, and after exposure, 1973 and
1976 cohorts ${ }^{1}$

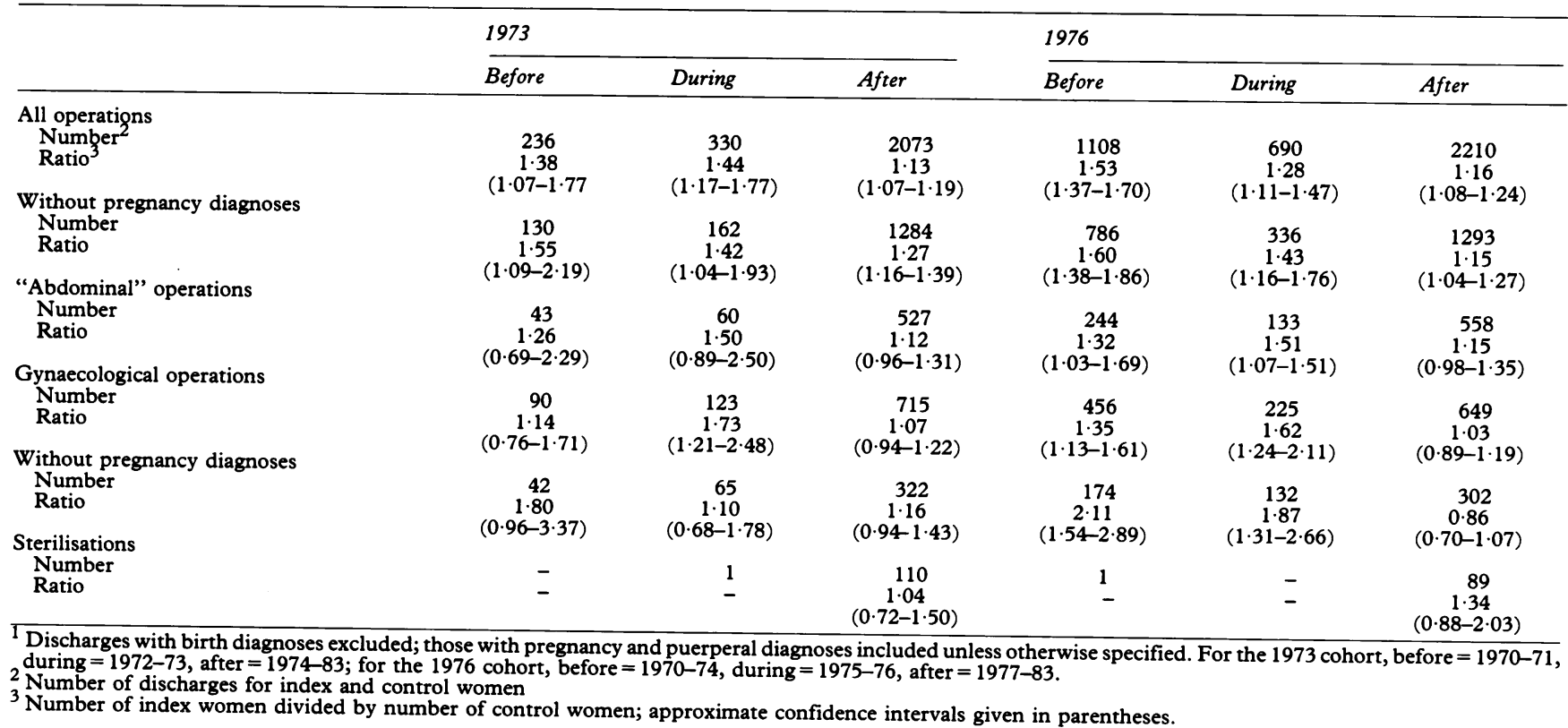


(Matching for the child's sex was done for a study on subsequent fertility ${ }^{5}$ and is not relevant here.) Because of the scantiness and inadequate quality of the data in the birth registry, we could not control all potential predictors of health. As a proxy we used hospital admissions before the first birth. But this does not guarantee that the index and control women were similar in characteristics which express their health effects only later in life and/or only after a birth.

Second, discharges from hospitals were used as a measure of health. This leads to several reservations: (1) In the case of general hospitals, discharges are likely to correspond with admissions each year. But in the case of mental hospitals, some women may have stayed a long time or may not have been discharged at all during the follow up. (2) It is mainly serious problems that lead to hospital admission. This is not a drawback as such, but if a previous caesarean section influences a doctor's judgement of seriousness, a bias is introduced. Susceptibility for use of services may then have been measured rather than health. For operations this is not a problem (an operation is a health problem, whatever the causes behind it), nor is it a problem for ectopic pregnancies which usually lead to hospital admission. (3) Additional diagnoses found during a hospital admission for other reasons were also included as specific diagnoses. Some of the increased ratios for urinary tract and neurological diagnoses during exposure may be explained by this. (4) The same women may have been included several times for the same problem, if they were discharged in between. But there is no need to suspect varying practices between index and control women, and analyses including each woman only once each year do not suggest that these multiple inclusions were a problem for the conclusions.

Third, the registry of general hospitals did not cover all hospitals, and the interpretation was based on the assumption that after their first delivery index and control women were referred equally to hospitals covered by the registry. This assumption is very plausible, but there is no empirical evidence that it is true. Another cause of reduced coverage is incorrect coding of personal identification numbers in the registries. Mistakes in coding of diagnoses may have influenced the occurrence of individual diagnoses, but are unlikely to have had much effect on the total number of discharges.

Fourth, the sickest women were excluded from the original cohorts. It is possible that caesarean sections have more negative health effects among women already sick or with an inclination to poor health. This analysis may thus underestimate the negative health effects of caesarean sections.

This study has three implications. First, the possible negative health effect on a mother is an additional reason for reducing caesarean section rates in areas with high rates. Second caesarean section may be a new aetiological factor for ectopic pregnancies, needing further, individually based studies with full potential to control for confounding variables. Third, poor mental health as a possible risk factor and consequence of caesarean sections is worth further study.

I thank Jan Gunnarskog and Anders Ericson, Swedish National Board of Health and Welfare, for the data, and Maili Malin and Jaana Niittylä for their help in preparing this article. The study was supported by a grant from the Academy of Finland.

1 Placek PJ, Taffel SM, Moien M. 1986 C-sections rise WBACs inch upward. Am $\mathcal{F}$ Public Health 1988; 78: 562-4. Notzon FC, Placek PJ, Taffel SM. Comparison of national cesarean-section rates. $N$ Engl f Med 1987; 316: 386-9.

3 Zdeb MS, Therriault GD, Logville VM. Frequency, spacing and outcome of pregnancies subsequent to primary cesarean childbirth. Am $尹$ Obstet Gynecol 1984; 150: 205-12.

4 Hemminki E, Graubard BI, Hoffman HJ, Mosher WD, Fetterly $\mathrm{K}$. Cesarean section and subsequent fertility: results from the 1982 National Survey of Family Growth Fertil Steril 1985; 43: 520-8.

5 Hemminki E. Effects of cesarean section on fertility and abortions. $\mathcal{F}$ Reprod Med 1986; 31: 620-4.

$6 \mathrm{LaSala}$ AP, Berkeley AS. Primary cesarean section and subsequent fertility. Am $\mathcal{f}$ Obstet Gynecol 1987; 157: subsequen

7 Hemminki E, Glebatis DM, Therriault GD, Janerich DT Incidence of placenta previa and abruptio placentae in New York State. NY State f Med 1987; 87: 594-8.

8 Garel M, Lelong N, Kaminski M. Psychological consequences of caesarean childbirth in primiparas. $f$ Psychosom Obstet Gynaecol 1987; 6: 197-209.

9 Garel M, Lelong N, Kaminski M. Follow-up study of psychological consequences of caesarean childbirth. Early Hum Devel 1988; 16: 271-82.

10 Hemminki E. Pregnancy and birth after cesarean section: a survey based on the Swedish birth register. Birth 1987; 14 $12-7$.

11 Socialstyrelsen. Utvärdering av innehållet $i$ medicinsk födelseregistrering (1974). Planeringsbyrå 3. Stockholm, 1977: 3 .

12 Kozak LJ, Andersen R, Andersen OW. The status of hospital discharge data in six countries. In: Vital and health statistics, Series 2, No 80. Department of Health, Education and Welfare publ No (PHS) 80-1354. Hyattsville, MD: OHEW, 1980: 41.

13 National Central Bureau of Statistics. Psychiatric inpatient care 1976. Statistical Reports HS: 1980: 20. Stockholm care 197.

14 Socialstyrelsen. Klassification av sjukdomar mm. 1968. Stockholm, 1982

15 Socialstyrelsen. Klassification av operationer MF 1970: 84 Stockholm, 1970

16 Schlesselman JJ. Case-control studies. New York: Oxford University Press, 1982: 44, 176.

17 Hemminki E, Heinonen PK. Time trends of ectopic pregnancies. Br $\mathcal{F}$ Obstet Gynaecol 1987; 94: 322-7.

18 Kallenberger DA, Ronk DA, Jimerson GK. Ectopic Pregnancy: a 15-year review of 160 cases. South Med $\mathcal{f}$ 1978; 71: 758-63.

19 Brenner PF, Roy S, Mishell DR. Ectopic pregnancy. A study of 300 consecutive surgically treated cases. $\mathcal{F} A M A$ 1980; 243: 673-6.

20 Hasan AA. Ectopic pregnancy: a seven-year survey. Eur $\mathcal{F}$ Obstet Gynecol Reprod Biol 1983; 16: 237-41.

21 Heinonen PK, Varjonen-Toivonen M, Komulainen M Pavonen J Kohdunulkoisen raskauden diagnostiikka ja hoito Duodecim 1984; 100: 1166-72, and additional unpublished data.

22 Nielsen TF \& Hökegård KH. The course of subsequent pregnancies after previous cesarean section. Acta Obstet pregnancies after previous cesa
Gynecol Scand 1984; 63: $13-6$.

23 Placek PJ, Taffel SM, Smith JC, Maze JM. Postpartum sterilization in cesarean section and non-cesarean section sterilization in cesarean section and non-cesarean section 1981; 71: 1258-61.

24 Kendell RE, Rennie D, Clarke JA, Dean C. The social and obstetric correlates of psychiatric admission in the obstetric correlates of psychiatric admis
puerperium. Psychol Med 1981; 11: 341-50. 